\title{
CdSe/ZnS Core-Shell System Enhance the Efficiency of the White Light Generation
}

\author{
Abdulla M. Suhail (Corresponding author) \\ Associate Professor Department of physics, College of science, University of Baghdad, Baghdad, Iraq \\ Tel: 964-770-871-0350 E-mail: Abdulla_shl@yahoo.com
}

Akeel M. Kadim

Department of physics, College of science, University of Baghdad, Baghdad, Iraq

Tel: 964-790-254-3700Ｅ-mail: akeel_a86@yahoo.com

Omar A. Ibrahim

Department of physics, College of science, University of Baghdad, Baghdad, Iraq

Tel: 964-790-187-9483 E-mail: omaradnan_1948@yahoo.com

Hind I. Murad

Department of physics, College of science, University of Baghdad, Baghdad, Iraq

Tel: 964-790-231-2469Ｅ-mail: Al-killani.hind@yahoo.com

Received: September 15, 2011 Accepted: September 29, $2011 \quad$ Published: February 1, 2012

doi:10.5539/apr.v4n1p57

URL: http://dx.doi.org/10.5539/apr.v4n1p57

\begin{abstract}
The synthesis techniques of highly luminescent $\mathrm{CdSe} / \mathrm{ZnS}$ core-shell composite nanocrystals are reported. The color-conversion, incorporating the photoluminescence emission of $\mathrm{CdSe} / \mathrm{ZnS}$ core-shell nanocrystals in blue $\lambda=350 \mathrm{~nm}$ and green $\lambda=520 \mathrm{~nm}$ on near UV-InGaN/GaN LED $\lambda=365 \mathrm{~nm}$, was studied. The generated white light resulting from color-mixing of the emitted wavelengths of the core-shell composite and that of the near UV emission from the LED was analyzed depending upon the chromaticity coordinates. The X-ray diffraction pattern was used to study the $\mathrm{CdSe} / \mathrm{ZnS}$ core-shell structure and the nanocrystal size formation. The absorption and photoluminescence spectra of the composite core-shell were investigated. The Gaussian fit was applied to the fluorescence spectrum of the $\mathrm{CdSe} / \mathrm{ZnS}$ core-shell in order to determine the chromaticity coordinates of the output white light emitted on the chromaticity diagram.
\end{abstract}

Keywords: CdSe/ZnS, White light generation, Core-Shell

\section{Introduction}

Since $25 \%$ of the global electricity consumption is used for lighting, the white light generation has attracted great interest for saving the electrical energy consumption in order to reduce the operating expense Tsao, J .Y. (2002). The solid-state lighting (SSL) by using the tradition phosphor is not new and deferent schemes have been reported to generate white light Mueller et al (2005) and Chen et al (2005). One of the most popular ways is the blending of red, green and blue phosphors in appropriate ratio to generate the white light Ali et al (2007). The importance of the SSL not only due to its financial benefits, but because the SSL is predicted to reduce the carbon emission highly which leads to clean environment. The energy efficiency of SSL in converting electricity into light is about 50\% whereas for traditional lamp it is around $1 \%$. In addition, SSL offer ultra-long lifetimes for the lamps and the source becomes, ragged and compact.

The white nanoluminophors have attracted more attention for their potential use in solid-state lighting. Usually, the materials used in white nanoluminophors are semiconductors like $\mathrm{CdS}, \mathrm{CdSe}, \mathrm{ZnS}$ and $\mathrm{ZnSe}$ with size in order of 1-10 nm Bowers et al (2005). Since the nanostructure have a large number of surface atoms compare 
with the bulk, the characteristics of the surface atoms have more effect on the main physical and chemical properties of the material. The surface states appear as trap-states in the main energy gap of the nanosemiconductor; are responsible for the high quantum efficiency radiation emitted visible wavelength up on illuminating it by UV radiation Nizamoglu et al (2008).

Highly luminescent II-VI semiconductor nanocrystals or colloidal quantum dots (QDs) are interesting materials because of their applications in optoelectronics, nonlinear optics, and biology. It is known that the photoluminescence (PL) efficiency of QDs can be significantly improved by growing a shell of a wide-band gap semiconductor around the QDs core by analogy with two-dimensional semiconductor heterostructures Baranov et al (2003).

The emission from the trap-rich nanocrystals are much useful than that from the doped-semiconductor nanocrystals. The CdS quantum dots were prepared by a colloidal technique offering an accepted size distribution to generate a white light when it is illuminated by UV radiation Suhail et al (2010).

Since the white light generated from the trap-rich requires a specific size distribution in order to generate the white light in an accepted color index values under the UV illumination, the specific size distribution technique required highly controlled reaction temperature and reaction time. It is a bit difficult to optimize such conditions to produce the required nanosize distribution, which leading to low yield quantum dot products.

The core-shell materials consist of a core structural domain covered by a shell domain. The core and shell may be composed of variety of materials including polymers, inorganic solids, and metals; they have properties, which may be different from the core or the shell materials Darbandi (2007).

One of the important characteristics of semiconductors concerns the influence of the surface on the optical and electrical properties, and the need to embed semiconductors clusters in a passivating medium. It is well known that the photoluminescence (PL) emission intensity of CdSe QDs increases several times when the CdSe cores are capped inside a shell of high band gap material like $\mathrm{ZnS}$ to form a $\mathrm{CdSe} / \mathrm{ZnS}$ core-shell structure Nguyen (2010).

In this work, the $\mathrm{CdSe} / \mathrm{ZnS}$ core-shell nanostructures are produced using a simple chemical method in order to generate the white light with accepted quantum efficiency.

\section{Experimental Work}

\subsection{Preparation of colloidal CdSe nanoparticles}

The cadmium selenide CdSe nanoparticles were prepared as a colloidal by chemical reaction of sodium selenosulfide $\mathrm{Na}_{2} \mathrm{SeSO}_{3}$ of $20 \mathrm{mM}$ and cadmium chloride $\mathrm{CdCl}_{2}$ with gelatin of $40 \mathrm{mM}$ solutions at 1:2 mole ratio. The $\mathrm{Na}_{2} \mathrm{SeSO}_{3}$ solution was prepared by dissolving $0.504 \mathrm{~g}$ of $\mathrm{Na}_{2} \mathrm{SO}_{3}$ in $100 \mathrm{ml}$ distilled water, followed by the addition of $0.158 \mathrm{~g}$ selenium Se powder to the $\mathrm{Na}_{2} \mathrm{SO}_{3}$ solution. After that, the mixture has been heated to $80^{\circ} \mathrm{C}$ and maintained at this temperature for three hours. Finally, the $\mathrm{Na}_{2} \mathrm{SeSO}_{3}$ solution was sealed and saved in the dark. The $\mathrm{CdCl}_{2}$ with gelatin solution was prepared by dissolving $0.438 \mathrm{~g}$ of $\mathrm{CdCl}_{2}$ in $50 \mathrm{ml}$ distilled water, followed by addition $0.1 \mathrm{~g}$ of gelatin. The mixture was then heated to $50^{\circ} \mathrm{C}$ for 5 minutes. Ammonium hydroxide was used to adjust the $\mathrm{pH}$ of the solution to the required $8.4 \mathrm{pH}$ level. The two solutions $\left(\mathrm{CdCl}_{2}\right.$ with gelatin and $\mathrm{Na}_{2} \mathrm{SeSO}_{3}$ ) were mixed in a three-neck flask and left on magnetic stirrer at $25^{\circ} \mathrm{C}$ with continuous flowing of argon gas for 30 minutes, until the formation of CdSe nanostructures.

\subsection{Preparation of colloidal $\mathrm{ZnS}$ nanoparticles}

The zinc sulfide $\mathrm{ZnS}$ nanoparticle were prepared by mixing two chemical solutions of 0.1 M.The first one, was prepared by dissolving $0.27 \mathrm{~g}$ of zinc chloride powder $\mathrm{ZnCl}_{2}$ in $20 \mathrm{ml}$ distilled water. While the second solution was obtained by dissolving $0.156 \mathrm{~g}$ from sodium sulfide powder $\mathrm{Na}_{2} \mathrm{~S}$ in $20 \mathrm{ml}$ distilled water. The two solutions were mixed in a three-neck flask and were left on magnetic stirrer at room temperature with continuous flowing of argon gas for about one hour until the $\mathrm{ZnS}$ nanoparticles were formed.

\subsection{Preparation of CdSe/ZnS core-shell nanoparticles}

The CdSe/ZnS core-shell nanostructures were prepared by chemical reaction of $12 \mathrm{ml} \mathrm{CdCl}_{2}$ with gelatin solution and $6 \mathrm{ml} \mathrm{Na}_{2} \mathrm{SeSO}_{3}$ solution at 2:1 molar ratio in three- neck flask, followed by the addition of $20 \mathrm{ml}$ of $\mathrm{ZnS}$ solution. The solutions mixed in the three-neck flask were left on magnetic stirrer at $50{ }^{\circ} \mathrm{C}$ temperature with continuous flowing of argon gas for about one hour until the $\mathrm{CdSe} / \mathrm{ZnS}$ core-shell nanostructures were formed and then, isopropanol was added followed by centrifugation.

\subsection{Preparation of $\mathrm{CdSe} / \mathrm{ZnS}$ core-shell in polyamide nylon}

One gram of polyamide nylon was dissolved in $15 \mathrm{ml}$ Tri hydrogen fluoride THF. The mixture was stirred at 
room temperature for 30 minutes to get a homogeneous solution. The colloidal CdSe/ZnS core-shell nanostructures were added to the polymer solution by syringe with continuous stirring for 15 minutes until it becomes homogeneous. The mixture ( $\mathrm{CdSe} / \mathrm{ZnS}$ core-shell and the polymer solution) was poured into Petri dish to form a film of $\mathrm{CdSe} / \mathrm{ZnS}$ in polyamide nylon.

\section{Test of the Prepared Sample}

\subsection{Structure study}

SHIMADZU XRD-6000 recorded the X-ray diffraction pattern of CdSe/ZnS nanoparticle powder. The system use $\left(\mathrm{Cu} \mathrm{K} \alpha\right.$ radiation line of wavelength of $1.54 \AA$ in $2 \theta^{\circ}$ range from $\left.10 \theta^{\circ}-70 \theta^{\circ}\right)$.

\subsection{Absorption and Photoluminescence (PL) spectra}

The UV-VIS absorption spectra of the samples were recorded by OPTIMA SP-3000 UV-VIS spectrophotometer in the spectral range (200-1100) $\mathrm{nm}$. The photoluminescence (PL) spectrum in the above mentioned spectral range was taken by SL 174 spectrofluorometer.

\section{Results and Discussion}

The X- ray diffraction pattern of the yield $\mathrm{CdSe} / \mathrm{ZnS}$ core-shell nanoparticles is illustrated in figure 1 . The pattern shows three peaks centered around $26.3^{\circ}$ for (111) plane whereas the other two peaks were centered around $\left(42.85^{\circ}\right)$ and $\left(50^{\circ}\right)$. The appearance of the three mentioned peaks was observed by several other authors Baranov (2003), Dabbousi et al (1997), Schumacher et al (2009).The broadening of the apparent X-ray diffraction peaks indicates that the $\mathrm{CdSe} / \mathrm{ZnS}$ core-shells are in nanodimension. Using the width of (111) peak in Scherer relation John et al (2010), Gupta et al (2009), Ramalingam et al (2008) and Singh et al (2010):

$$
\mathrm{D}=\frac{0.9 \lambda}{\beta \cos \Theta}
$$

Where $\mathrm{D}$ is the grain size, $\lambda$ is the ( $\mathrm{Cu}$ k $\alpha$ radiation line wavelength), $\beta$ represents the full width at half maximum (FWHM) in degree and $\theta$ is the diffraction angle. The size of the formed core-shell nanoparticle was found to be about $2 \mathrm{~nm}$.

The UV-VIS absorption spectrum of the colloidal CdSe/ZnS core-shell nanoparticle is shown in figure 2. The spectrum shows that the sample is highly absorbed in the UV region whereas it still absorbed in the visible region up to $550 \mathrm{~nm}$ and it becomes transparent beyond this wavelength. It can be noticed from the figure that there are two inflection points the first one around $360 \mathrm{~nm}$ and the other was around $400 \mathrm{~nm}$. These two inflection points are related to the forbidden gap of the $\mathrm{ZnS}$ and the shallow band formed due to the uncompleted $\mathrm{ZnS}$ shell.

The energy gaps of the composite $\mathrm{CdSe} / \mathrm{ZnS}$ core-shell nanoparticles are shown in figure 3 . It can be noticed from the figure that there are two energy gaps centered around 2.3 and $3.5 \mathrm{eV}$. These two values are related to the forbidden gaps in CdSe and $\mathrm{ZnS}$ respectively.

The room temperature emission spectrum of the $\mathrm{CdSe} / \mathrm{ZnS}$ core-shell nanoparticles in colloidal sample excited by $280 \mathrm{~nm}$ line is shown in figure 4 . The figure shows two high intensity peaks centered around $350 \mathrm{~nm}$ and 520 $\mathrm{nm}$, which can be referred to the direct band transition of the $\mathrm{ZnS}$ and the CdSe compound material. The observed low intensity peaks may be attributed to the formation of the surface states, which is related to the uncompleted covering of the CdSe core by the $\mathrm{ZnS}$ shell. The low intensity peak observed around $600 \mathrm{~nm}$ may be related to the surface states formation in $\mathrm{CdSe} / \mathrm{ZnS}$ core-shell system.

The illumination of the colloidal samples of $\mathrm{CdSe} / \mathrm{ZnS}$ core-shell dispersed in polyamide nylon and distilled water by UV-LED of $5 \mathrm{~mW}$ are shown in figure 6 . The figure shows that the brightness of the emitted white light from the core-shell dispersed in polyamide nylon is higher than that observed from CdSe/ZnS core-shell dispersed in the colloidal.

Since the colure of light is expressed by the CIE colorimetry system, the spectrum of a given light is weighted by the XYZ color matching function Nag et al (2007). The resultant of the three weighted integral values of X, Y, and $\mathrm{Z}$ are calculated from the photoluminescence spectrum by finding the area under the curve for the three peaks in red, green and blue centered around 350, 520 and $600 \mathrm{~nm}$. The chromaticity coordinates $\mathrm{x}, \mathrm{y}$ on CIE colorimetry system is found from $\mathrm{X}, \mathrm{Y}$ and $\mathrm{Z}:-$

$$
\begin{aligned}
& \mathrm{x}=\mathrm{X} /(\mathrm{X}+\mathrm{Y}+\mathrm{Z})=0.40 \\
& \mathrm{y}=\mathrm{Y} /(\mathrm{X}+\mathrm{Y}+\mathrm{Z})=0.43
\end{aligned}
$$


Where $\mathrm{X}, \mathrm{Y}$, and $\mathrm{Z}$, are the area under the Gaussian curves of the emitted red, green and blue in the photoluminescence spectrum.

The white light, which produced from our $\mathrm{CdSe} / \mathrm{ZnS}$ core-shell nanoparticles, has chromaticity coordinates (x, y) $=(0.40,0.43)$.

We can verify the correlated color temperature (CCT) for the resulting white light by using McCamy's approximation algorithm to estimate the CCT from the x, y chromatic ties C.S. McCamy's (2007):

$$
\mathrm{CCT}=-449 \mathrm{n}^{3}+3525 \mathrm{n}^{2}-6823.3 \mathrm{n}+5520.33 \ldots
$$

Where

$$
\mathrm{n}=\mathrm{x}-0.3320 / \mathrm{y}-0.1858
$$

Referring to the calculated chromaticity coordinates, the CCT was found to be about $3886 \mathrm{~K}$ by using McCamy's approximation algorithm. This temperature value was calculated by using CCT calculator and the result was $3892 \mathrm{~K}$, which is not far away from the result predicted by the McCamy's approximation. This discrepancy in the temperature values may be attributed to the ignoring of the high order terms in the McCamy's algorithm. The values of the chromaticity coordinates was used in chromaticity diagram as shown in figure 6 . The figure shows that the output white light is in the warm white light region.

\section{Conclusion}

$\mathrm{CdSe} / \mathrm{ZnS}$ core-shell nanoparticles are successfully produced in a good quality and sufficient quantity by the chemical reaction route. The optical properties (the absorption spectrum and the photoluminescence spectrum) are studied showing the appearance of the band-to-band transition of $\mathrm{CdSe}$ and $\mathrm{ZnS}$. Moreover, the surface defects have enhanced the emission appearance of the surface state in the photoluminescence spectrum. The white light emission was obtained by illuminating the $\mathrm{CdSe} / \mathrm{ZnS}$ core-shell nanocrystals with GaN LED UV radiation. The chromaticity coordinates of the produced white light were located at $(0.40,0.43)$ in the CIE colorimetry.

\section{References}

Ali, M., Chattopadhyay, S., Nag, A., Kumar, A., Sapra, S., Chakraborty S., \& Sarma, D. D. (2007). White-Light Emission from A blend of CdSeS Nanocrystals of Different Se: S Ratio. Nanotechnology, 18. 075401. http://dx.doi.org/10.1088/0957-4484/18/7/075401

Baranov, A. V., Rakovich, Yu. P., Donegan, J. F., Perova, T. S., Moore, R. A., Talapin, D. V., Rogach, A. L., Masumoto, Y., \& Nabiev, I. (2003). Effect of ZnS Shell Thickness on the Phonon Spectra in CdSe Quantum Dots. Physical Review. B, 68. 165306: 1-7. http://dx.doi.org/10.1103/PhysRevB.68.165306

Bowers, M. J. II., McBride, J. R., \& Rosenthal, S. J. (2005). White-Light Emission from Magic-Sized Cadmium Selenide Nanocrystals. J. Am. Chem. Soc., 127(44). 15378-15379. http://dx.doi.org/10.10221/ja055470d

Chen, H. S., Wang, S. J. J., Lo, C. J., \& Chi, J. Y. (2005). White-Light Emission from Organics-Capped ZnSe Quantum Dots and Application in White-Light-Emitting Diodes. Appl. Phys. Lett., 86. 131905:1-3. http://dx.doi.org/10.1063/1.1886894.

Dabbousi, B. O., Rodriguez-Viejo, J., Mikulec , F. V., Heine, J. R., Mattoussi, H., Ober, R., Jensen , K. F., \& Bawendi, M. G. (1997). (CdSe)ZnS Core-Shell Quantum Dots: Synthesis and Characterization of A size Series of Highly Luminescent Nanocrystallites. J. Phys. Chem. B, 101. 9463-9475.

Darbandi, M. (2007). Silica Coated Nanocomposites. Ph.D.dissertation. Albert-Ludwig's-University, Freiburgb im Breisgau/Germany, p.22.

Gupta, P., \& Ramrakhiani, M. (2009). Influence of the Particle Size on the Optical Properties of CdSe Nanoparticles. The Open Nanoscience Journal, 3, 15-19.

John, R., \& Sasiflorence, S. (2010). Optical, Structural and Morphological Studies of Bean- Like ZnS Nanostructures by Aqueous Chemical Method. Chalcogenide Letters, 7(4). 269-273.

McCamy, C. S. (2007). Correlated Color Temperature as an Explicit Function of Chromaticity Coordinates. Color Res. Appl., 17, 142-144.

Mueller, A. H., Petruska, M. A., Achermann M., Werder, D. J., Akhadov, E. A., Koleske, D. D., Hoffbauer, M. A., \& Klimov, V. I. (2005). Multicolor Light-Emitting Diodes Based on Semiconductor Nanocrystals Encapsulated in GaN Charge Injection Layers. Nano Lett., 5(6). 1039-1044. http://dx.doi.org/10.1021/n1050384x

Nag, A., \& Sarma, D. D. (2007). White Light from Mn2+-Doped CdS Nanocrystals: A new approach. J. Phys. 
Chem. Letters. C, 111, 13641-13644. http://dx.doi.org/10.1021/jp074703f

Nguyen, H. Q. (2010). Synthesis and Optical Properties of CdSe Nanocrystals and CdSe/ZnS Core/Shell Nanostructures in Non-Coordinating Solvent. Adv. Nat. Sc. Nanosci. Nanotechnol, 1. 025004: 1-4. http://dx.doi.org/10.1088/2043-6254/1/2/025004

Nizamoglu, S., Zengin, G., \& Demir, H. V. (2008). Color-Converting Combinations of Nanocrystal Emitters for Warm-White Light Generation with High Color Rendering Index. Appl. Phys. Lett., 92. 031102: 1-3

Ramalingam, G., Christy, P. D., Jothi, N. S. N., Kumar, T. R., Selvakumar, S., \& Sagayaraj, P. (2008). Synthesis, Structural and Optical Properties of CdSe Nanorods for Nanophotonics Applications. PHOTONICS-2008: International Conference on Fiber Optics and Photonics December 13-17, 2008, IIT Delhi, India.

Schumacher, W., Nagy, A., Waldman, W. J., \& Dutta, P. K. (2009). Direct Synthesis of Aqueous CdSe/ZnS-Based Quantum Dots Using Microwave Irradiation. J. Phys. Chem. C, 113, 12132-12139. http://dx.doi.org/10.1021/jp901003r

Singh, R. S., Bhushan, S., \& Singh, A. K. (2010). Studies on Nano-Crystalline Properties of Chemically Deposited CdSe Films. Chalcogenide Letters, 7(6). 375-381.

Suhail, A. M., Khalifa, M. J., Saeed, N. M., \& Ibrahim, O. A. (2010). White Light Generation from CdS Nanoparticles Illuminated by UV-LED. J. App. Phys, 49. 3060: 1-5. http://dx.doi.org/10.1051/epjap/2010005

Tsao, J .Y. (2002). Light Emitted Diodes (LEDs) for General Illumination. OIDA technology report. Sandia National Laboratories, NM.

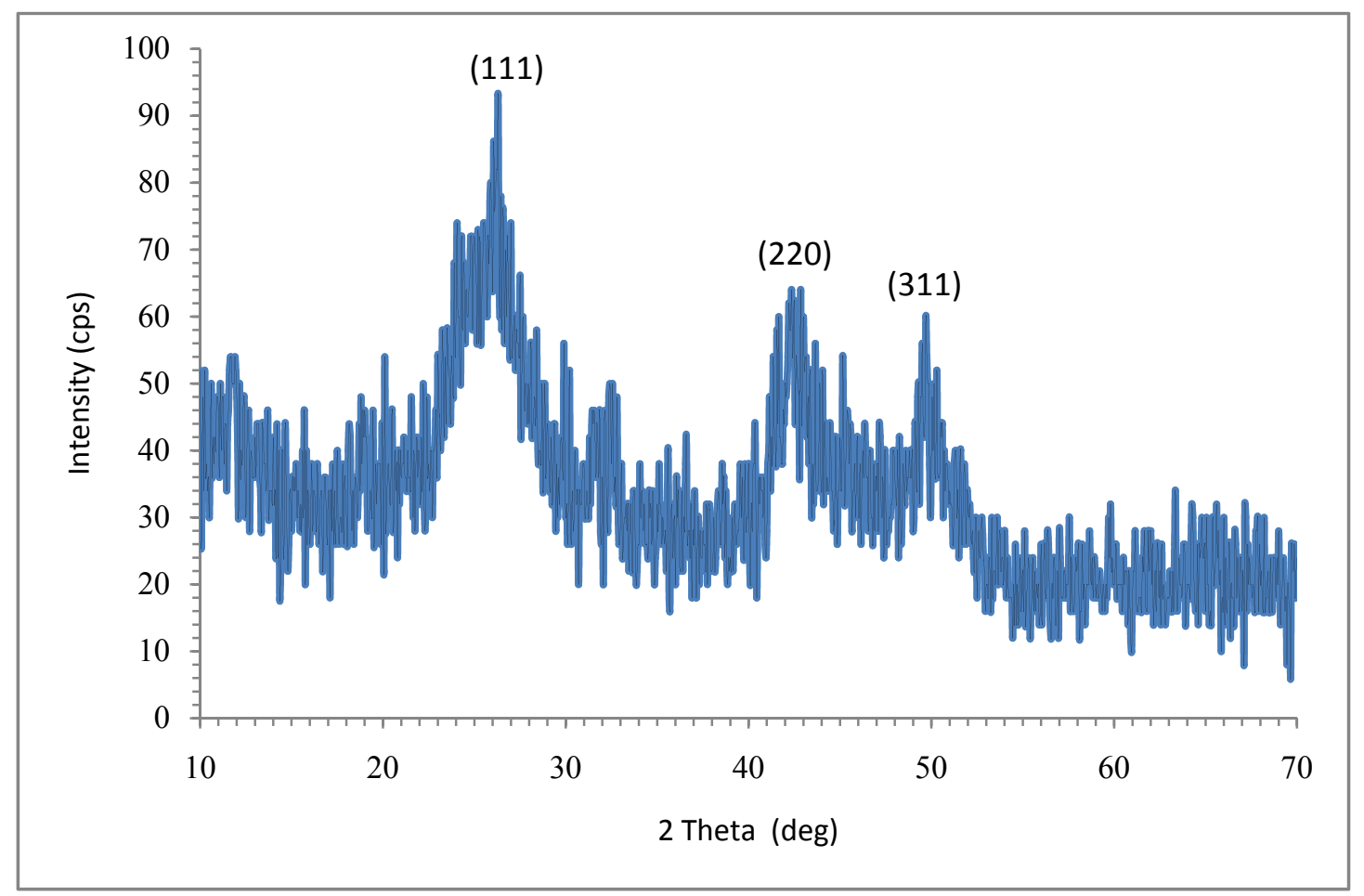

Figure 1. The XRD pattern of CdSe/ZnS core-shell nanoparticles 


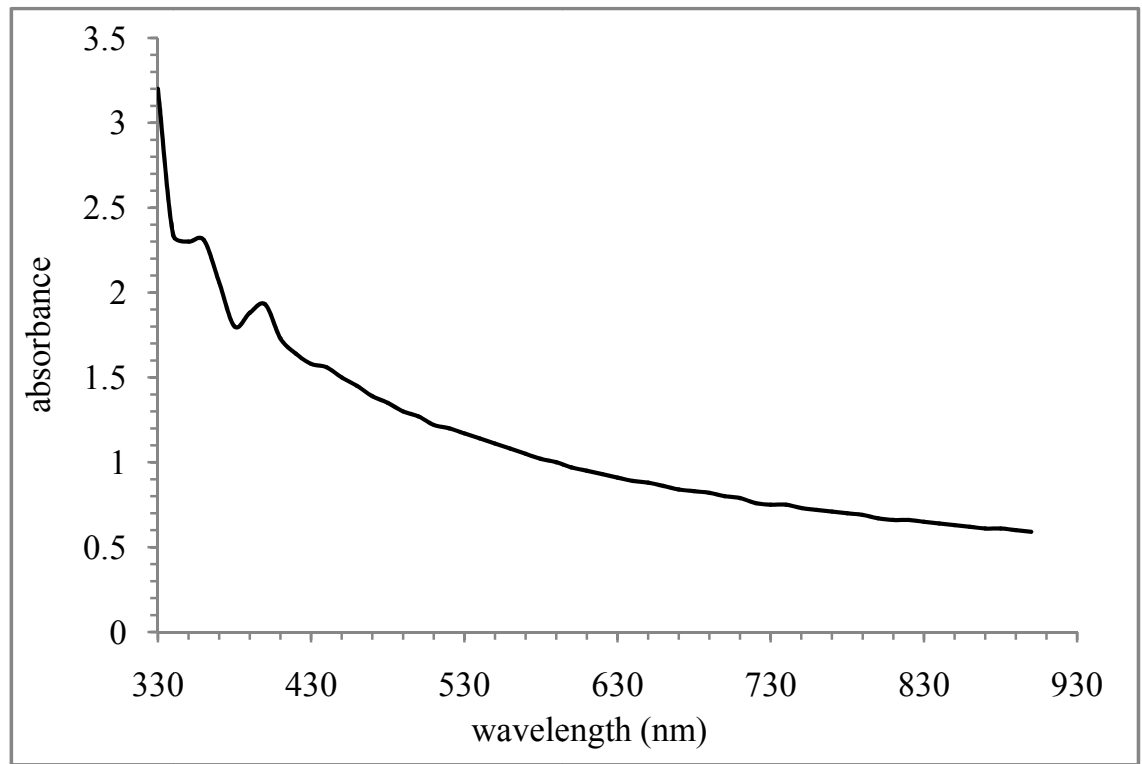

Figure 2. UV-VIS absorption spectrum of $\mathrm{CdSe} / \mathrm{ZnS}$ core-shell nanoparticles

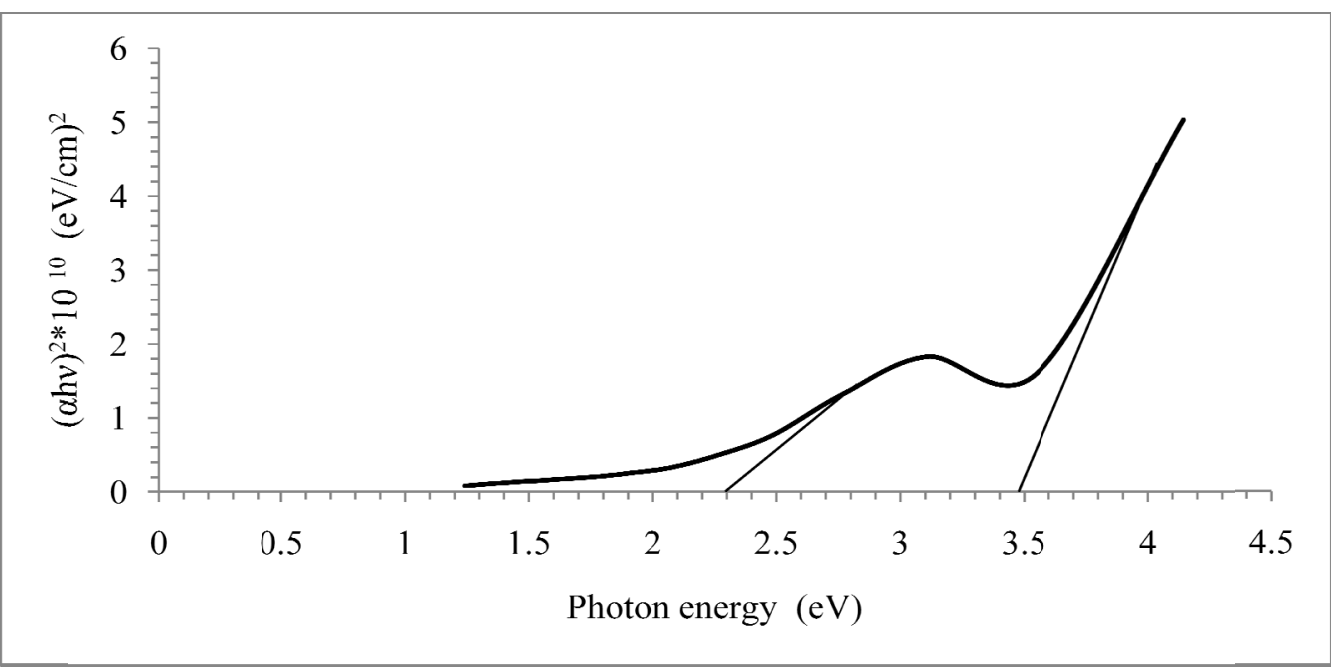

Figure 3. Energy gap of $\mathrm{CdSe} / \mathrm{ZnS}$ core-shell nanoparticles

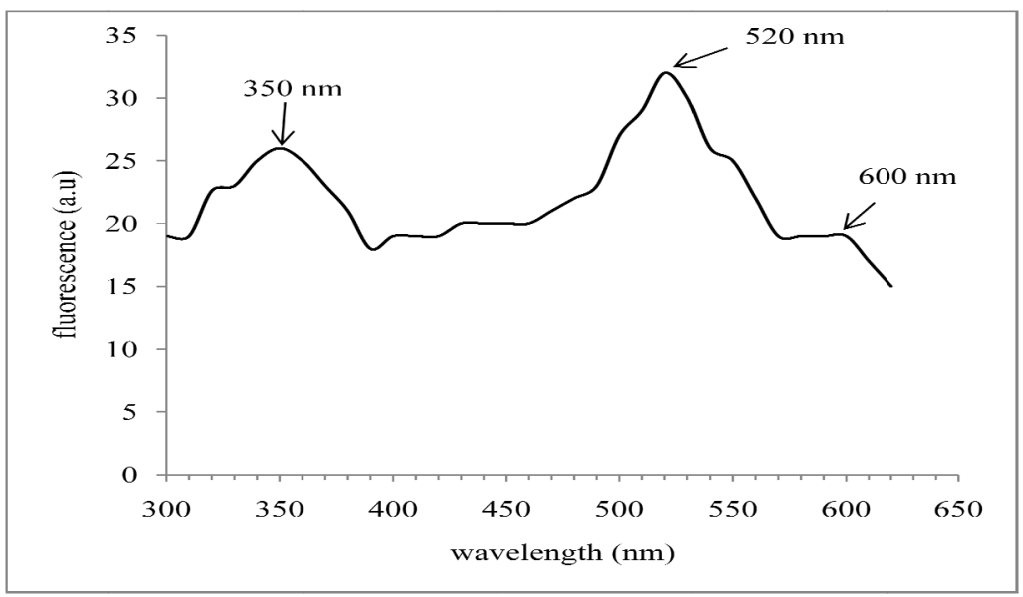

Figure 4. Photoluminescence emission spectrum of $\mathrm{CdSe} / \mathrm{ZnS}$ core-shell solution $(\lambda \mathrm{ex}=280 \mathrm{~nm})$ 


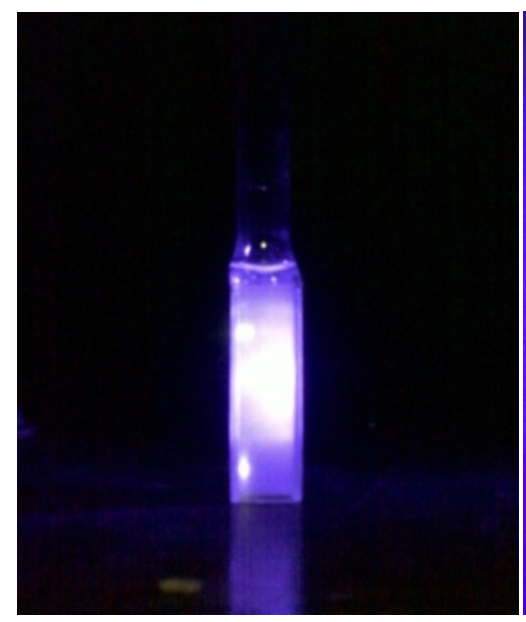

(a)

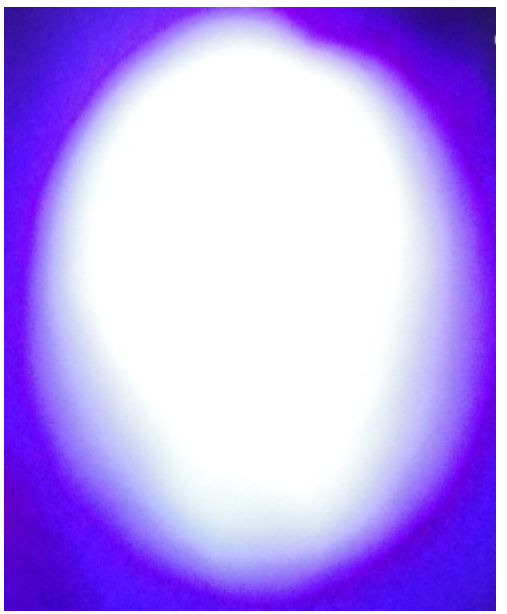

(b)

Figure 5. A photograph of white light generation by GaN-UV LED (a) CdSe/ZnS core-shell solution (b) $\mathrm{CdSe} / \mathrm{ZnS}$ core-shell in polyamide nylon

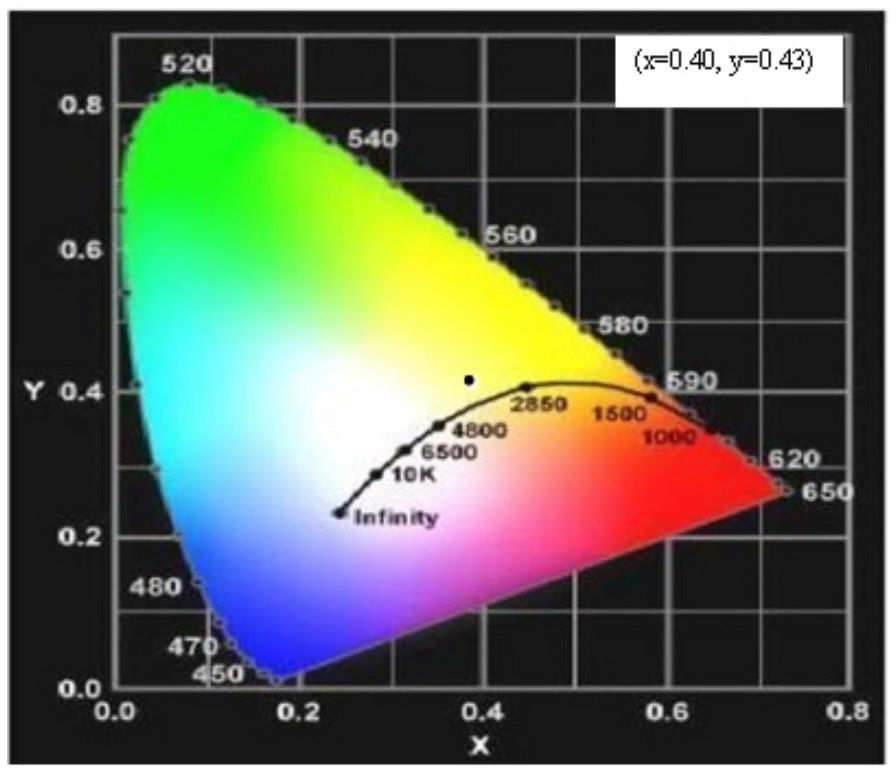

Figure 6. Chromaticity coordinates of $\mathrm{CdSe} / \mathrm{ZnS}$ core-shell nanoparticles $(\mathrm{x}=0.40, \mathrm{y}=0.43)$ on the CIE in 1931 chromaticity diagram 